\title{
Price Competition in Australian Telecommunications
}

\section{Jan Muir, Brad Jennings and Fiona McAnally}

$\mathrm{T}$

he removal of many of the previous barriers to entry in the Australian telecommunications market on 1 July 1997 set the pre-conditions for increased competition in that market. With twenty-eight carriers and numerous carriage service providers now licensed to operate in a market previously served by just three carriers and a few service providers, that opportunity has become a reality. The structure of the market is clearly more competitive than before.

The new competitive structure is not, however, an end in itself. It was intended to promote the long-term interests of end-users and 'over time... [to] lead to a significant reduction in prices and major improvements in the breadth and the quality of services, both for business and residential customers' (Alston, 1997). Such outcomes result not from increased competition per se, but rather from changes in the behaviour of market participants. The purpose of this article is to consider one aspect of competitive behaviour - pricing strategies and to examine its evolution over the eighteen months following 1 July 1997.

The Communications Research Unit has observed the standard, published prices of a range of operators in the Australian telecommunications market in four six-monthly 'snapshots', the first of which was taken on 30 June 1997. This article is based on the results of those observations. Price changes which occurred before 1 July 1997 were not included in the analysis. The Australian Competition and Consumer Commission recently published the results of a study of changes in Telstra's telecommunications charges between 1992 and 1998 (ACCC, 1998).

We begin this article by examining how, where and how much prices have changed in the Australian telecommunications market since 1 July 1997. We then consider how these changes have altered the structure of Australian telecommunications pricing. We conclude by examining the implications of these developments for consumers and for the state of competition in the market more generally.

Jan Muir and Brad Jennings are with the Communications Research Unit of the Department of Communications, Information Technology and the Arts. Fiona McAnally worked on this project during an assignment with the former Bureau of Transport and Communications Economics. 


\section{Methodological Note}

We have confined our attention to eight operators Telstra, Optus, AAPT, One.Tel, Telegroup, Primus, WorldXchange and Tele2000. This selection includes the two incumbent carriers, some of the larger of the new entrants targeting residential as well as business markets and several of the price leaders in those markets.

Long distance call charges were considered in three distance zones (short, medium and long distance) and two time zones (most expensive and least expensive times to call). Very short distance zones, including community and pastoral call zones, were not considered on this occasion.

International call charges were analysed for a set of fourteen countries, five of which are depicted in the charts which accompany this article. Included were heavily-trafficked destinations such as New Zealand, the UK, the US; a number of European countries (Germany, Greece, Ireland); and Canada. Also included was a range of regional destinations, with both well-developed and less well-developed telecommunications networks (Japan, Singapore, Hong Kong, Vietnam, Indonesia, Malaysia and China).

The analysis is confined to the standard rates charged by operators (the rates automatically available to subscribers when a call is made). However, permanent or temporary discounts are widely available in the market. Such discounts lower the prices available to consumers and so offer the potential for gain beyond the changes in standard prices which we report.

In the case of Telstra and Optus, the prices of services are shown in four 'snapshots', taken at six-monthly intervals from June 1997 (immediately prior to deregulation) to December 1998. (Price reductions which took effect after December 1998 are excluded from the analysis.) For newer entrants, prices shown are those effective at December 1998.

The data on which the analysis is based were drawn exclusively from the published tariffs and promotional material of the operators concerned.

\section{Price Movements Since 1 July 1997}

The new entrants in the Australian telecommunications market operate almost exclusively in the long distance and international call markets. No new carriers have been licensed in the mobile telecommunications market since July 1997, although several new operators now offer services in competition with the licensed carriers and new digital networks are planned. There is little effective competition to Telstra in the provision and maintenance of local telephone lines, 
although Optus's broadband service is now reported to have over 200000 local telephony subscribers (Optus Communications, 1999).

For these reasons, we concentrate in this section on changes in the prices of long distance and international services, and to a lesser extent on mobile services.

Long distance, international and mobile call charges in Australia typically have a fixed component (a flagfall) which is triggered as the call connects, and a variable component which is related to the length of the call. This variable component itself normally has three dimensions, being influenced by:

- The time of day at which the call is made,

- The distance zone within which the call is made, and

- The length of the call.

The relative importance of each of these dimensions in the total cost of the call is one indication of whether call charges are changing in structure.

\section{Long distance calls}

Long distance calls are the largest component of timed telephone traffic in Australia, generating well in excess of $\$ 3$ billion in revenue in 1997-98 (Telstra, 1998; Optus, 1998; Vodafone, 1998; AAPT, 1998). This volume of business, together with the (assumed) relatively high degree of price responsiveness for this type of call, means that rate changes can be expected to generate significant turnover changes in the market.

\section{Incumbent operators}

Long distance charges were among the first to change after 1 July 1997 . Charts 1a and $1 \mathrm{~b}$ show the rate changes introduced by the two major incumbent operators, Telstra and Optus, during the three six-month periods which followed, while Charts $2 \mathrm{a}$ and $2 \mathrm{~b}$ show the long distance call charges of the range of operators considered.

It is clear that neither Telstra nor Optus offered blanket price falls. Both carriers increased the up-front (flagfall) component of their call charges and lowered peak hour charges in the long distance zone $(>745 \mathrm{~km})$. Both increased charges in shorter distance zones during at least some time periods. Optus left its off-peak rates unchanged, while Telstra altered prices across its range. Telstra also reduced the number of hours subject to peak rate charges from 50 per week in June 1997 to just 30 per week twelve months later, effectively lowering charges for calls made during the resulting reclassified periods. 
Chart 1a Changes to long distance charges since July 1997 - Telstra (cents per minute)

Most expensive time to call

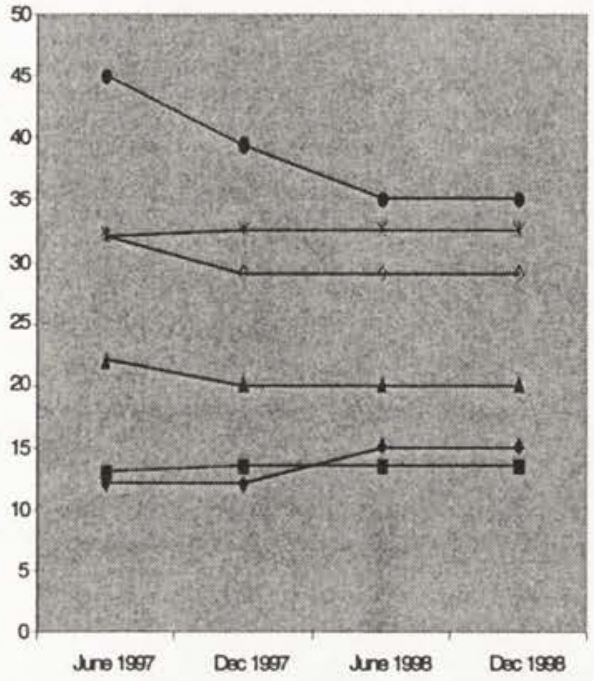

Least expensive time to call

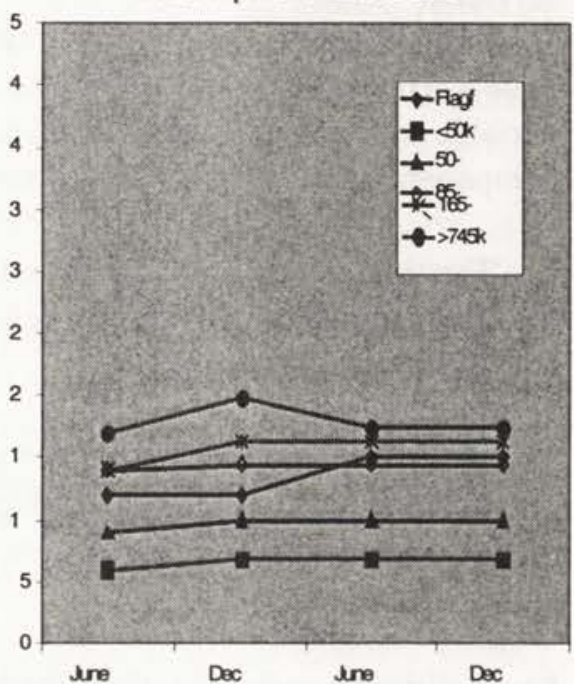

Chart $1 b \quad$ Changes to long distance charges since July 1997 - Optus (cents per minute)

Most expensive time to cal!

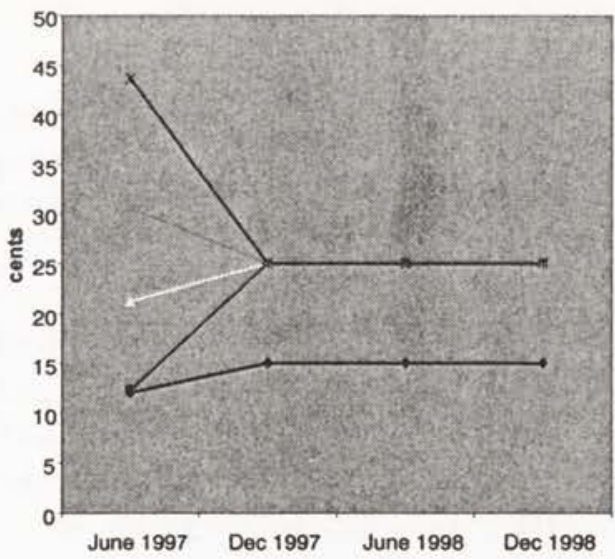

Least expensive time to call

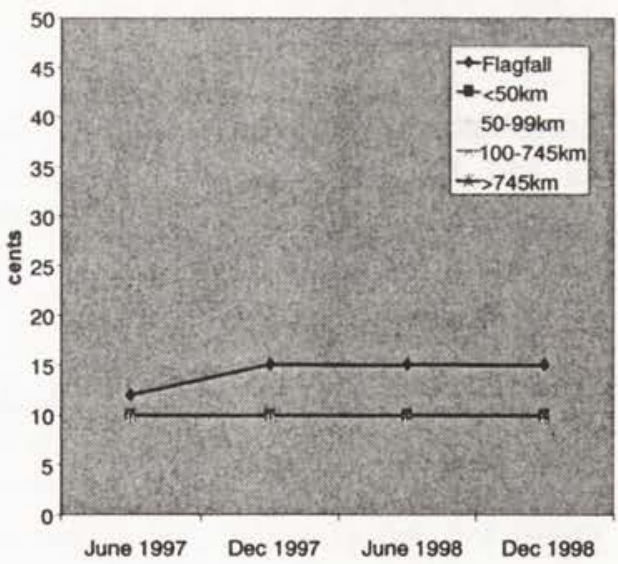

Note: As per minute call charges have been identical across distance zones since December 1997 for calls made during the most expensive times, and throughout the entire period considered for calls made during the least expensive times, the rates are depicted on the charts as superimposed lines. 
Chart $2 a \quad$ Long distance charges at December 1998 - Selected operators, most expensive time to call (cents per minute)

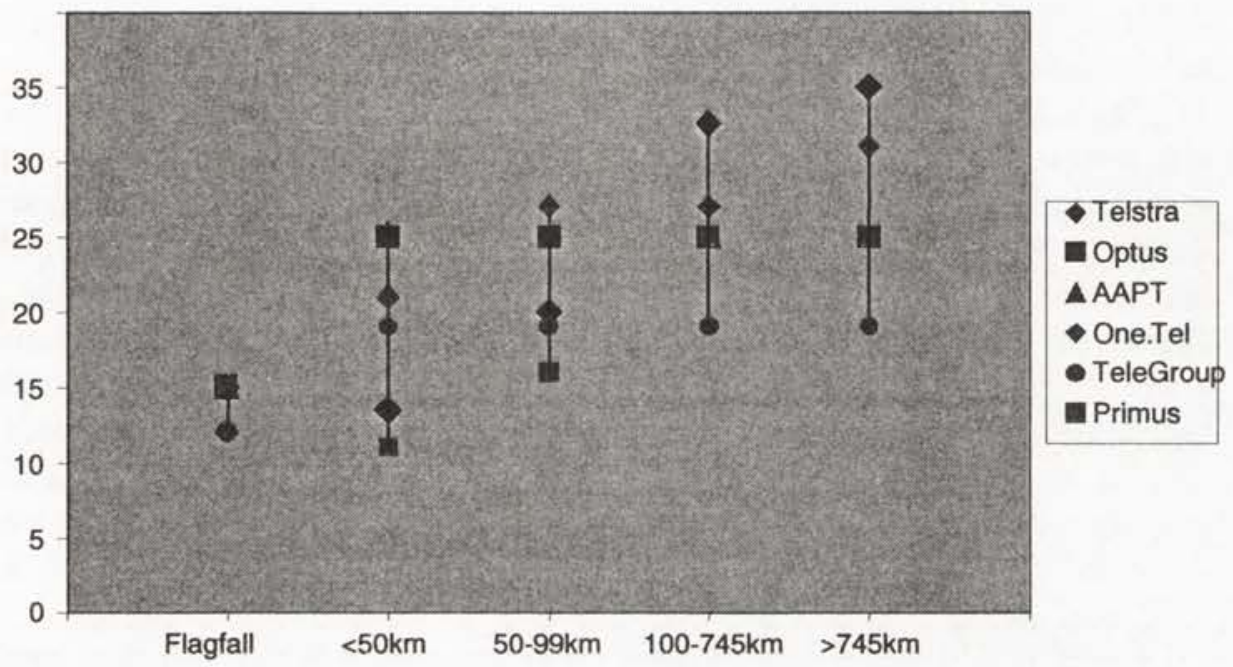

Chart $2 b \quad$ Long distance charges at December 1998 - Selected operators, least expensive time to call (cents per minute)

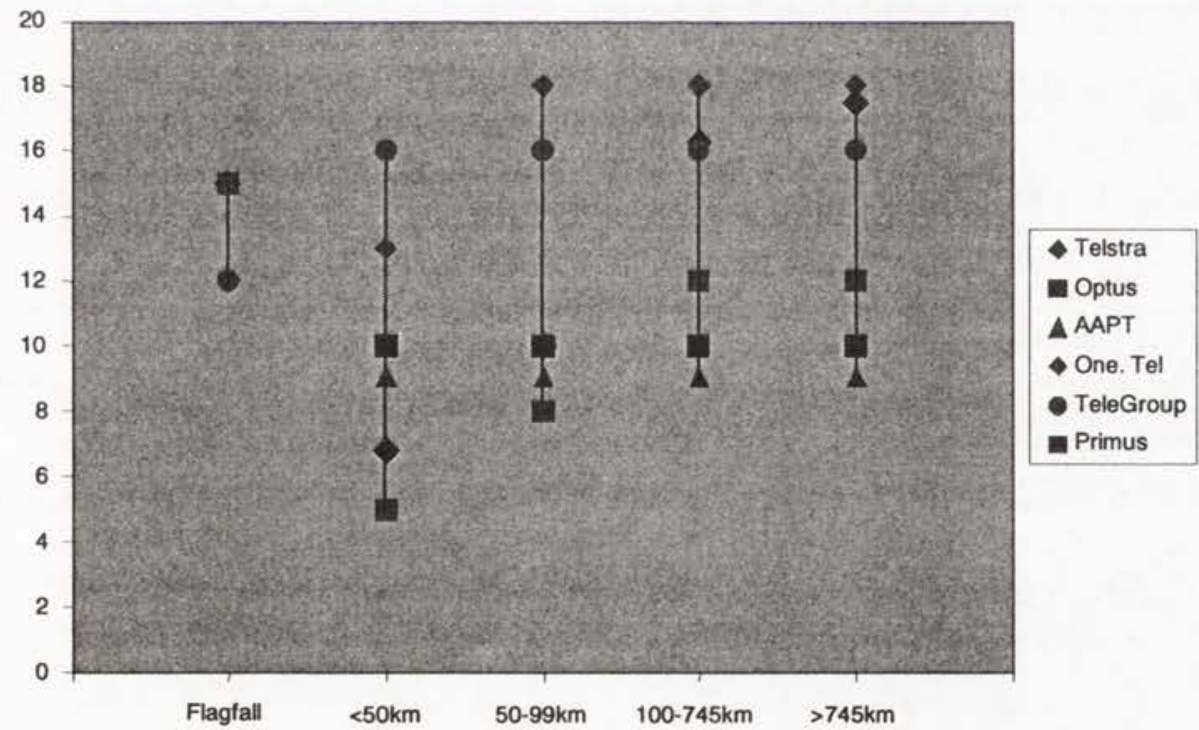


Both carriers made the bulk of their changes within the first six months following the deregulation, and very few changes in the subsequent 12 months. (In December 1998, Telstra announced reductions to be introduced in January 1999 in its standard per minute rates for STD calls of 15 per cent on average across all distance bands. These changes coincided with the withdrawal of Telstra's basic Flexi-Plans. The changes are not considered here as they were not in place at the time of our December 1998 'snapshot'.)

These changes have altered the structure of long distance charging by the incumbent operators. The premiums which apply to calls made during peak periods and calls to more distant destinations have shrunk in almost all cases, as shown in Tables 1 and 2. Optus has suppressed its distance zones completely, introducing flat per minute charges for all long distance call destinations, and Telstra has reduced the number of its distance zones and made them uniform across time zones. The premium attached to long-held calls has also fallen following the increase in flagfall charges. The availability of capped call charges at certain times of day also suggests that up-front costs (switching, recording, etc) are more important in charging criteria than call length, particularly when business is being sought among traditionally lower-volume residential users.

The price changes have had other consequences. For the first time since its entry into the Australian telecommunications market in 1991, Optus has introduced a pricing regime across all time zones which no longer simply shadows that of Telstra. Its price structure is now simpler than Telstra's and oriented towards attracting long-haul traffic in both peak and non-peak periods. Each of the carriers has time slots in which it is clearly cheaper than the other. The prices charged by the incumbent carriers have diverged, rather than converged, over the last eighteen months.

\section{Table 1: Time-Of-Call Premium in Long Distance Call Charging, Telstra and Optus}

Ratio of per minute charge for a peak pefiod call to per minute charge for a weekend call, June 1997 and December 1998

\begin{tabular}{lcccc}
\hline CALL DESTINATION & \multicolumn{2}{c}{ TELSTRA } & \multicolumn{2}{c}{ OPTUS } \\
& June 1997 & Dec 1998 & June 1997 & Dec 1998 \\
\hline Short distance $^{1}$ & 2.44 & 2 & 2.12 & 2.5 \\
\hline Long distance $^{2}$ & 2.65 & 2 & 4.36 & 2.5 \\
\hline
\end{tabular}

Notes:

1 Telstra $50-85 \mathrm{~km}$, Optus $50-99 \mathrm{~km}$.

$2>745 \mathrm{~km}$. 


\section{Table 2: Distance Premium in Long Distance Call Charging, Telstra and} Optus

Ratio of per minute charge for a long distance call to per minute charge for a short distance call, June 1997 and December 1998

\begin{tabular}{lcccc}
\hline TIME OF DAY OF CALL & \multicolumn{2}{c}{ TELSTRA } & \multicolumn{2}{c}{ OPTUS } \\
& June 1997 & Dec 1998 & June 1997 & Dec 1998 \\
\hline Most expensive time to call $^{1}$ & 2.05 & 1.75 & 2.06 & 1 \\
\hline Least expensive time to call $^{2}$ & 1.89 & 1.75 & 1 & 1 \\
\hline
\end{tabular}

Notes:

1 For Telstra, weekdays $8 \mathrm{am}$ to $6 \mathrm{pm}$ (June 1997), weekdays 7am to $1 \mathrm{pm}$ (December 1998); for Optus, weekdays 8am to 6pm.

2 For Telstra, weeknights 8pm to 8am and all weekends (June 1997), weeknights 8pm to 7am and all weekends (December 1998); for Optus, 6pm Friday to 8am Monday (June 1997), midnight Friday to midnight Sunday (December 1998).

3 Non-intercapital calls. Lower rates apply to intercapital destinations.

\section{New entrants}

Newer operators have positioned themselves around these rates. A number of operators have, like Optus, chosen to forego distance-based charging and others are clearly targeting either peak or non-peak callers. At the end of December 1998, Telegroup and AAPT were generally competitive in longer-haul calls (peak and off-peak respectively), while Primus was more competitive in shorthaul calls. The cheapest operator in each category is shown at the base of the bar; the variation in these operators indicates that there was no clear price leader among the operators considered.

The pricing of national long distance calls is, as a result, more varied than it was eighteen months ago. While blanket price reductions have not occurred, many calls were much less expensive to make at the end of 1998 than in mid1997 , and the redefinition of peak periods had also lowered call costs for many customers. However, the range of call charges and the lack of clear price leaders suggests that customers may need to be prepared to use multiple operators if they wish to minimise the cost of calls made at standard rates.

\section{International Calls}

Outgoing traffic in the international call market generates only around one-tenth of the traffic in the national long distance market, but because of high per minute revenues, generates a much larger share of call revenues. Unlike charges for calls to domestic destinations, international call charges include a component paid to the carrier in the destination network for terminating calls in 
that network. This component - the settlement rate - is determined in bilateral agreements within a framework established in international fora, and so is a cost outside the control of any individual operator. (A useful summary of the arrangements is contained in Industry Commission, $1997 \mathrm{~b}: \mathrm{Ch} .4)$.

The international call market has been targeted by new entrants and significant rate changes have occurred.

\section{Incumbent carriers}

Telstra and Optus entered the deregulatory period with broadly similar price schedules for international calls (a selection of which are shown in Charts 3a and 3b). Optus's prices shadowed those of Telstra, with charges generally 3 to 5 per cent below Telstra in most of the markets considered.

As was the case with long distance charges, Telstra and Optus responded differently to the new market conditions. Six months into the deregulation period, Telstra had made no changes to its peak period charges for the countries considered, and only isolated changes to off-peak charges. Optus had also left its peak and off-peak charges largely unchanged, but had introduced a weekend schedule with charges up to 60 per cent below its peak rates. Telstra responded during the second six months by overhauling its entire range of charges, reducing many of its day and night rates and introducing a weekend schedule with substantially lower charges. During the third six-month period, both companies reverted to a two time zone schedule, with weekday and weekend rates only, and the previous weekday daytime prices reduced to the level of weekday night time rates. In December 1998, Telstra reduced all its standard per minute rates for International Direct 0011 and 0015 calls by a further 15 per cent. Both operators continued to engage in the extensive promotion of 'special' rates which applied for limited periods of time.

The outcome is different from that observed in the long distance market. Unlike that market, the restructuring of charges related to the simplification of time rather than distance-based charges, and neither incumbent raised any rate in the set of call destinations considered during the post-deregulation period. Again unlike the national long distance market, no real pattern is observable in the changes, except that the largest falls occurred in off-peak times, possibly indicating competition for new business among more price responsive off-peak callers. Further, the rate structures of the two carriers remain more or less comparable in general terms: the countries which are most and least expensive to call using Telstra are generally the same countries which are most and least expensive to call using Optus. However, in a reversal of the trend observed in each of the earlier 'snapshots', Telstra was the cheaper carrier for most destinations in December 1998 (before Optus's discount arrangements were considered). 
Chart 3a Changes to international call charges since July 1997 - Telstra
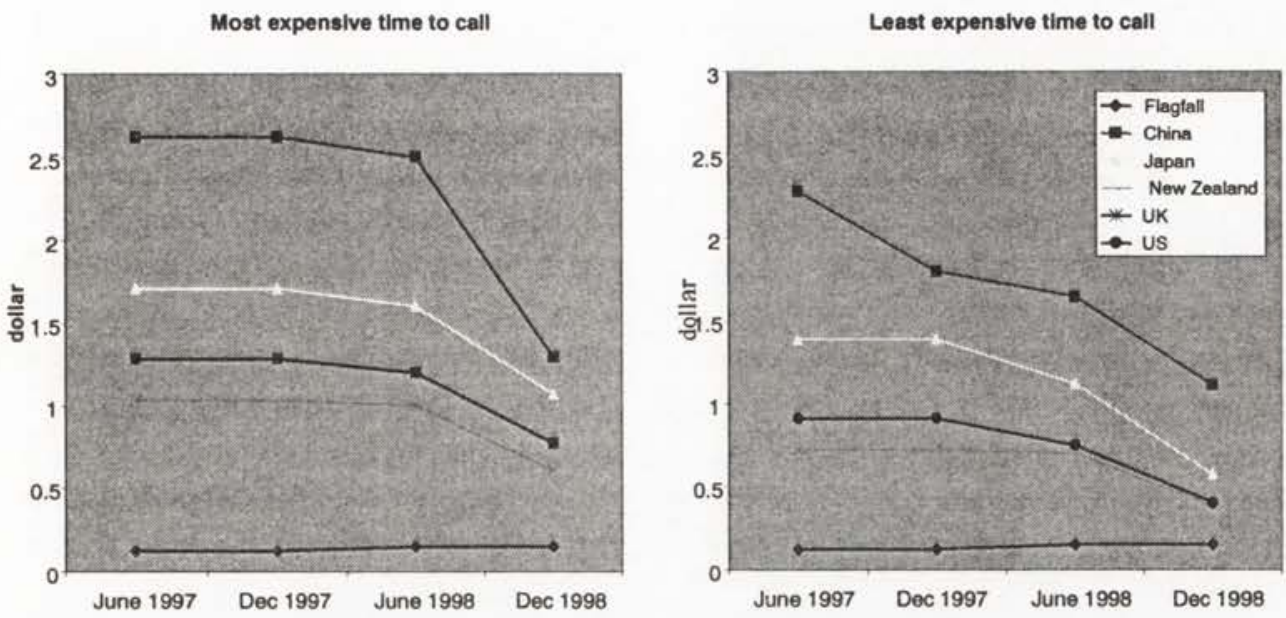

Chart 3b Changes to international call charges since July 1997 - Optus
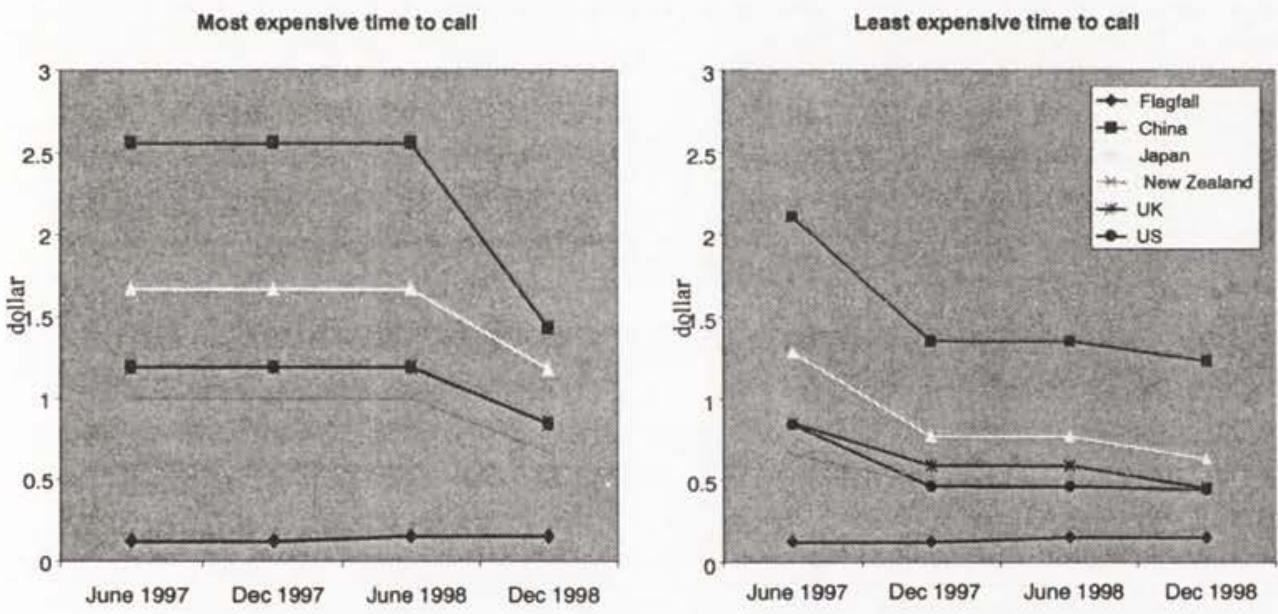

Note: For Optus, per minute charges for calls to the US and New Zealand have been approximately equal since December 1997 during the least expensive time to call and hence overlap on the chart. The per minute charge for calls to the US has fallen to equal that rate in the most recent six-monthly survey. 
Chart 4 International call charges at December 1998 - Selected cperators.

International - most expensive time to call

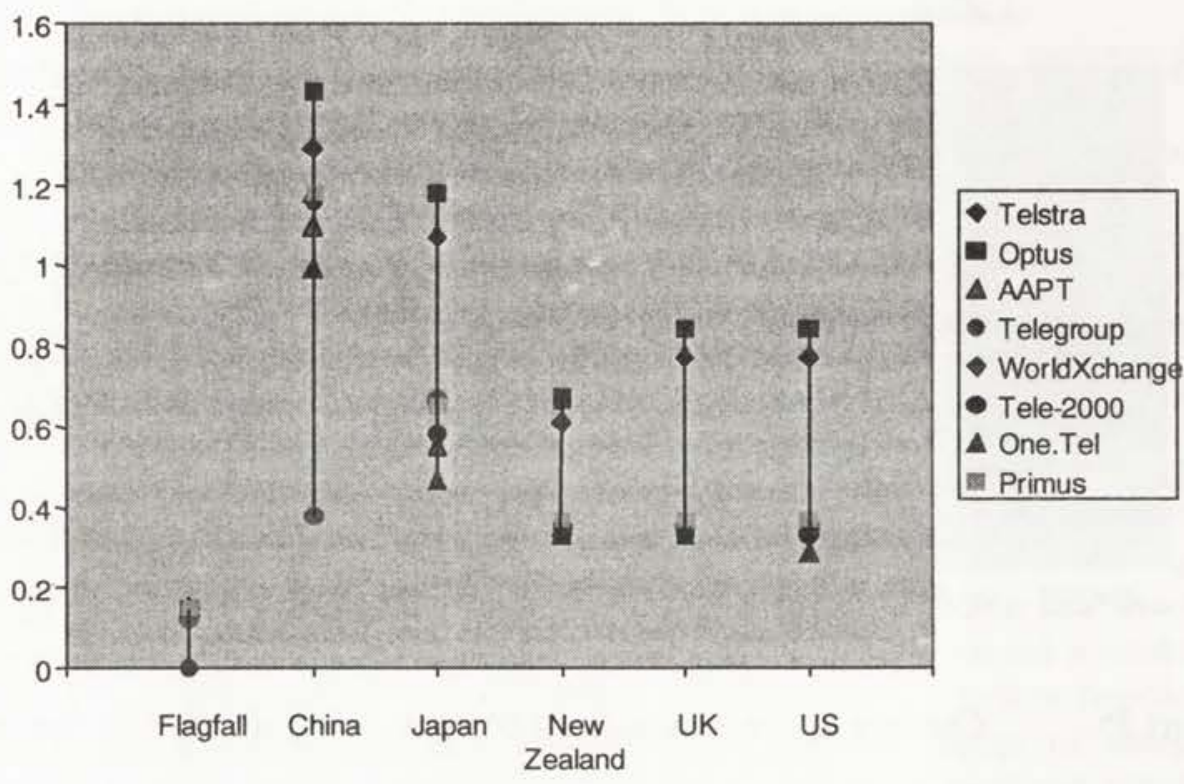

International - least expensive time to call

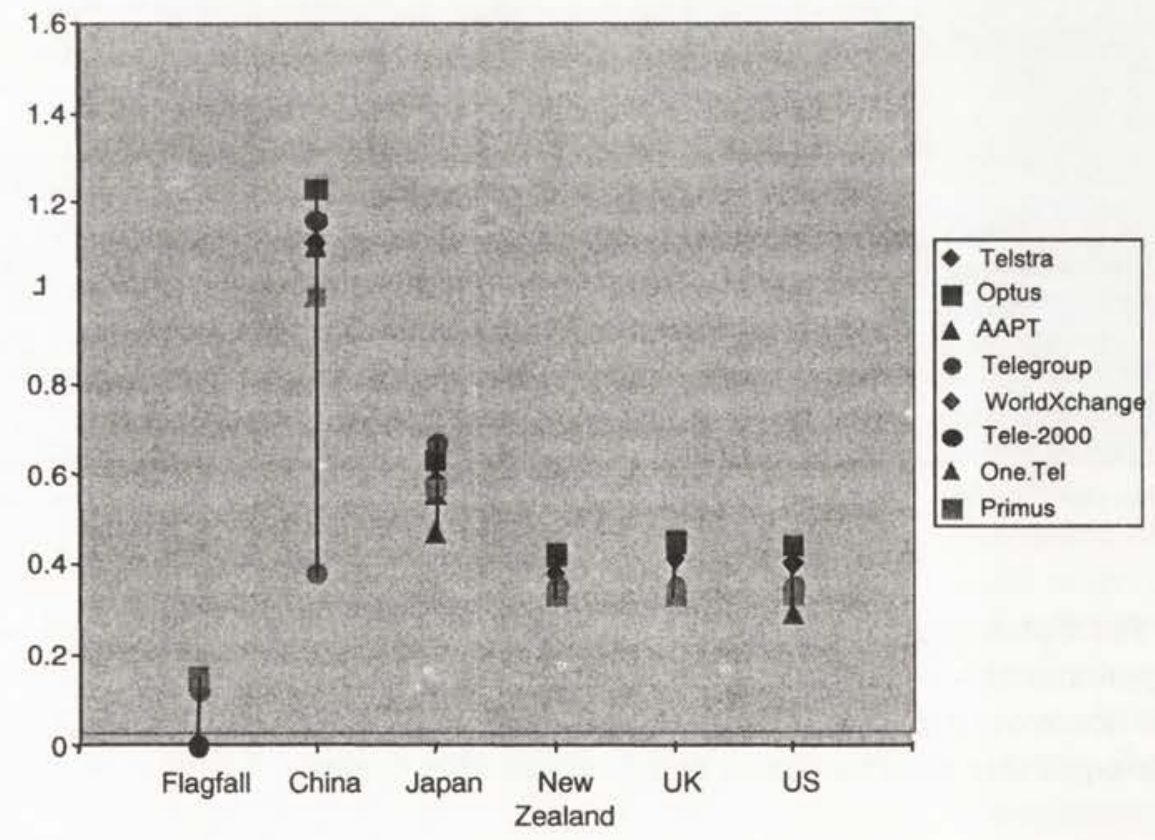


The introduction of weekend rates at a considerable discount on weekday charges has increased the time-of-call premium attached to most international calls made during weekdays (Table 3 ). This premium had been reduced by Telstra and (in some distance zones) by Optus in respect of long distance calls in the second half of 1997. The size of the premium is smaller for international calls than for national long distance calls.

There appears to be no direct counterpart in the international call market to the distance premium evident in Telstra's national long distance charging. Countries in Australia's region are not (with the exception of New Zealand) generally cheaper to call than more distant countries. Given the external influences on international call charges (which include negotiated settlement rates with other countries), this may not be surprising. Traffic volumes, demand patterns and the characteristics of the destination country's telecommunications markets, networks and regulatory structures may be more important determinants of charges.

\section{Table 3: Time-Of-Call Premium in International Call Charging, Telstra and Optus}

Ratio of per minute charge for a peak period call (selected destinations) to per minute charge for a weekend call to those destinations, June 1997 and Dec 1998

\begin{tabular}{lcccc}
\hline DESTINATION OF CALL & \multicolumn{2}{c}{ TELSTRA } & \multicolumn{2}{c}{ OPTUS } \\
& June 1997 & Dec 1998 & June 1997 & Dec 1998 \\
\hline $\begin{array}{l}\text { Destinations with relatively } \\
\text { high per minute charges }\end{array}$ & & & & \\
$\quad$ China & 1.15 & 1.16 & 1.21 & 1.16 \\
$\quad$ Japan & 1.23 & 1.88 & 1.30 & 1.87 \\
\hline $\begin{array}{l}\text { Destinations with relatively } \\
\text { low per minute charges }\end{array}$ & & & & \\
$\quad$ New Zealand & 1.43 & 1.61 & 1.52 & 1.60 \\
$\quad$ United Kingdom & 1.41 & 1.88 & 1.4 & 1.87 \\
\hline
\end{tabular}

\section{New entrants}

Most new entrants to the Australian telecommunications market offer both long distance and international call services. Of the new entrants considered in this study, only WorldXchange and Tele2000 offer international services only. As in the long distance market, the new entrants have adopted pricing strategies which enable them to undercut Telstra and/or Optus in most of the time zones and destinations considered (Chart 4).

Eighteen months after deregulation, the range of standard per minute charges for a call to any given destination is considerable. It can cost as much as $84 \mathrm{c}$ per minute to call the UK or the US (Optus) or as little as $29 \mathrm{c}$ (Primus). 
When the lower or non-existent flagfall charges of some operators and the lack of any peak/off-peak differentiation in rates are considered, the standard charge for any given call can be seen to diverge even further.

Inter-country relativities are, however, fairly consistent. Some countries are always among the more expensive destinations of an operator (China, Indonesia and Vietnam, for example), while others are always among the cheapest (New Zealand, the UK and the US). No single operator is cheaper across the board than any other, although One.Tel is cheaper in more of the destinations considered than any other operator.

No time-of-call dimension now remains in the price structures of the new entrants considered, illustrating the extent to which those operators have diverged from traditional telecommunications price structures. AAPT moved from a peak/off-peak structure to flat rates between June and December 1998. As noted above, where a time dimension does exist (Telstra and Optus), the time-of-call premium is lower in international than in national long distance price structures.

A number of the new entrants have lowered some or all of their prices since entering the market, followed most recently by Telstra itself, whose across-theboard rate cuts took effect late in December 1998. One.Tel's rate reductions have been greater than those of some other operators, enabling it to overtake Primus as the operator with the cheapest rates overall.

\section{Mobile Services}

Since 1997, some increased competition in the mobile market has come from service providers reselling services from the three incumbent networks. Network stability, together with continuing strong demand for mobile services, has meant that there has, until now, been little new incentive for operators to engage in price competition. Handset pricing and, more recently, access charging, appear to be the main areas where carriers are competing strongly on price with the apparent intention of attracting new subscribers to their services. The proliferation of packages offering trade-offs between fixed and variable charges has increased the range as well as the complexity of choices now available to consumers. Airtime (per minute) charges themselves have shown less movement. Competition based on quality of service (notably network coverage and customer service), together with more general promotion of the benefits offered by mobile communications facilities, have been the strategies preferred.

Four new firms - AAPT, QUALCOMM, Hutchison and One.Tel acquired spectrum capable of delivering mobile telephony services in the 1998 auction of spectrum in the $800 \mathrm{MHz}$ and $1.8 \mathrm{GHz}$ spectrum bands. One.Tel and Hutchison are expected to begin rolling out their mobile networks shortly. 


\section{Overall Trends}

Price levels for telecommunications services in the more competitive areas of the Australian telecommunications market generally fell in the twelve months since the 1 July 1997 deregulation. A combination of price falls for calls with particular time and destination characteristics and the extension of the proportion of the week subject to off-peak and weekend rates brought this about. The range of charges offered for particular calls widened, with some operators offering services at rates less than half those of the incumbent carriers and Optus no longer simply 'shadowing' Telstra's rates. The incumbent carriers remained the more expensive operators in the market for most categories of services.

Call charging became less distance-dependent and somewhat less durationdependent than previously. National long distance calls are now charged by many operators at rates which vary only with the time the call is made and its duration; international calls are increasingly charged at rates which vary only with the destination of the call and its duration. Most operators reduced their standard call charges at least once in the eighteen months since deregulation, and also offer discounts for particular calling volumes or patterns and for time or destination-specific services, as well as temporary 'specials'.

\section{Emerging Price Structures}

The general declines in, and changing composition of, long distance and international charges, together with largely unchanged access, local call and mobile charges, have combined to alter the structure of prices for basic telecommunications services in Australia. With declining call charges for timed PSTN calls, fixed charges (network access) occupied a relatively larger proportion of expenditure on any telecommunications service bundle containing such calls than one year previously. The purchasing power of the telecommunications expenditure dollar has consequently increased.

These changes have been mirrored, albeit to a lesser extent, in the structure of prices for individual timed calls, where per minute charges dropped for most call categories while flagfall charges rose. Distance premiums fell in national long distance services. Time-of-call premiums have changed in different ways for different call categories and operators, but have been abandoned completely by the newer operators in the international call market with their flat-rate charging structures.

Both developments continue a trend towards structural change in telecommunications pricing which has been apparent for some time. The resulting price structures more closely approximate cost structures in the Australian telecommunications network (at least while it remains uncongested) than before. This effective 'rebalancing' of charges is likely to encourage greater use of the network by those prepared to pay at least the cost of switching 
and supporting additional calls. As the Industry Commission has pointed out, this has the potential to generate substantial benefits to consumers (Industry Commission, 1997a:App.C). The new price structures may also reflect the pattern of consumer demand for affected services, which is likely to be more price-responsive than the demand for access and local services, particularly among residential users, and less rapidly growing than the demand for mobile services.

\section{Conclusion}

The extent of the price changes which have been observed in newly competitive areas of the Australian telecommunications market suggests that prices have been used as a competitive weapon in the immediate post-deregulation period. Operators have clearly had both the capacity and the incentive to offer lower prices than those prevailing eighteen months earlier. The very limited range of price changes in areas without new competition probably reinforces this conclusion.

The level and structure of the price changes conform in general terms with those which might be expected in such circumstances. Prices have fallen in the market segments most affected by new entry, where profit margins are generally believed to have been high, and not in less competitive areas. The introduction of weekend rates and one-off 'special' rates at a considerable discount on peak period rates suggests that operators have sought to expand their markets by increasing use in uncongested periods rather than simply competing with each other for existing customers.

However, the range of prices which has emerged suggests that such competition is far from over. The persistence of inter-operator price disparities of the magnitude observed for many timed services suggests either lack of interest or awareness on the part of consumers of the 'menu' of prices on offer, or the existence of real or perceived disparities in the quality of the services themselves or their supplier. Alternatively, consumers may believe that the effort involved in identifying and evaluating the increasingly complex 'menu', and the complexity of switching service providers or using more than one operator, may exceed the benefits. It seems likely that the incumbent carriers, and Telstra in particular, have benefited to date from client loyalty or disinclination to risk association with a new supplier for the sake of a saving in telecommunications spending. This is particularly likely among customers for whom timed calls are small or irregular components of their telecommunications spending. Such reservations are likely to diminish as the new operators establish profile and reputation in the market and as consumers acquire experience in negotiating the range of services and rates on offer. Any subsequent changes in market share may then be expected to provoke a new round of competitive activity, whether price-based or more complex. 
Because the generally reduced prices for newly competitive services have not been offset by increased prices for less competitive basic carriage services, there appears to have been unambiguous gain to consumers. The extent of this gain is, however, difficult to estimate. Use of the services considered appears to have increased (Optus, 1998), but it is unclear to what extent that additional traffic has shifted to the new operators with their generally lower rate schedules. Customers who make such a switch and/or who are relatively intensive users of timed PSTN services will clearly have the potential to make more financial savings on any given call bundle than other customers. Unless they believe themselves to be accepting some reduction in service quality as a trade-off, they will be better off in consequence.

Whether suppliers have foregone significant profit as a result is unclear. Telstra's revenue per call minute for national long distance services remained almost unchanged at 23.6 cents in 1997-98 while revenue per outgoing minute of international services increased marginally to $\$ 1.96$ (Telstra, 1998), despite the reductions in per minute charges in both services. Changing call times, length and destination, possibly reflecting changing customer and traffic mixes, are likely to have accounted for this.

The next stage of the process is difficult to predict. On a practical level, if new price cap arrangements require Telstra to continue offering significant real price falls for basic carriage services over the next few years, then those falls will again be most likely to concentrate in areas where the incentive and the opportunity are greatest. Given current cost structures and market conditions, those areas are likely to include the more highly competitive services as well as, and increasingly, mobile services. More generally, competitive strategies aimed at the acquisition of customers rather than simply traffic may be favoured by operators seeking to develop core markets for higher-value and data-based products. Such strategies are likely to go well beyond the simplest forms of price competition.

Eighteen months after the deregulation of the telecommunications market, Australian telecommunications users have benefited from reductions in the prices of a range of telecommunications services, as well as from an extended range of services and service packages and wider choice of operators. While these benefits cannot be attributed solely to deregulation, it is clear that they have been encouraged, and almost certainly accelerated, by the more competitive operating environment post-July 1997. To that extent, the expectations of policy makers implementing the new competitive arrangements have been fulfilled.

The next eighteen months will be a period of consolidation for voice services in the Australian telecommunications market. It will be watched with interest. 


\section{References}

AAPT Telecommunications (1998), Annual Results www.aapt.com.au (accessed 15.12.98)

Alston, Senator the Hon Richard (1997), 'More jobs, cheaper phone calls, better quality services as Australia ushers in the new telecommunications era' (media release), 30 June.

Australian Competition and Consumer Commission (ACCC) (1998), Telecommunications Charges in Australia, Canberra, December.

Cable and Wireless Optus (1998), Prospectus.

Industry Commission (1997a), Telecommunications Economics and Policy Issues, Staff Information Paper, Canberra, March.

Industry Commission (1997b), International Telecommunications Reform in Australia, Staff Information Paper, Canberra, June.

Optus Communications (1998), Financial Data Book, Sydney, April.

Optus Communications (1999), 'Cable \& Wireless Optus delivers profit of $\$ 24$ million', (press release), Sydney, March.

Telstra Corporation (1998), Annual Report.

Vodafone (1998), 'Financial Accounts for year ending 31 March'.

This article is an updated version of a paper presented at the Communications Research Forum, Canberra, 24-25 September 1998. The authors thank their colleagues in the Department of Communications, Information Technology and the Arts and two anonymous referees for reviewing the paper and offering helpful comments and insights. The views expressed are, however, those of the authors and do not necessarily represent those of the Communications Research Unit or the Department of Communications, Information Technology and the Arts. 